\title{
A Parametric Study on the Effects of Ignition Timing, Spark Plug Type, and Exhaust Gas Recirculation on a Legacy 2-Stroke Lean Burn Natural Gas Engine
}

\author{
Nathaniel P. Fowler
}

Follow this and additional works at: https://researchrepository.wvu.edu/etd

\section{Recommended Citation}

Fowler, Nathaniel P., "A Parametric Study on the Effects of Ignition Timing, Spark Plug Type, and Exhaust Gas Recirculation on a Legacy 2-Stroke Lean Burn Natural Gas Engine" (2016). Graduate Theses, Dissertations, and Problem Reports. 5617.

https://researchrepository.wvu.edu/etd/5617

This Thesis is protected by copyright and/or related rights. It has been brought to you by the The Research Repository @ WVU with permission from the rights-holder(s). You are free to use this Thesis in any way that is permitted by the copyright and related rights legislation that applies to your use. For other uses you must obtain permission from the rights-holder(s) directly, unless additional rights are indicated by a Creative Commons license in the record and/ or on the work itself. This Thesis has been accepted for inclusion in WVU Graduate Theses, Dissertations, and Problem Reports collection by an authorized administrator of The Research Repository @ WVU. For more information, please contact researchrepository@mail.wvu.edu. 
The Transformation of Occupations:

A Case Study of Professionalism in Cocktail Bartending

\author{
Jacqueline Fowler
}

Thesis submitted to the Eberly College of Arts and Sciences at West Virginia University in partial fulfillment of the requirements for the degree of Master of Arts in Sociology

Jesse Wozniak, Ph.D., Chair Jason Manning, Ph.D. Corey Colyer, Ph.D.

Department of Sociology

\title{
Morgantown, West Virginia
} 2017

Keywords: professional, profession, professionalization, occupation, work, bartending, bartender, craft, cocktail, cultural capital, cultural intermediary, status, taste, preferences Copyright 2017 Jacqueline Fowler 


\section{ABSTRACT \\ The Transformation of Occupations: \\ A Case Study of Professionalism in Cocktail Bartending \\ Jacqueline Fowler}

One focus in the sociology of work and occupations literature concerns the phenomena by which occupations transform into skilled professions. This study focuses on a craft cocktail bar and the attending cocktail bartenders as a case study of occupational professionalization. Cocktail bartenders are uniquely suited for this type of inquiry, as many aspects of their occupation carry the markers of professionalism, such as mastery of a skill, a deep understanding of their field, and their potential to be cultural intermediaries.

This study utilizes observation and interviews to elucidate how bartenders define themselves, their work, and their occupation as a whole. By drawing on theories of human and cultural capital, professionalism, and creative work, the present study attempts to conceptualize and explain the processes that contribute to professionalization, especially in occupations that lack formal methods of gatekeeping or accreditation. 


\section{Table of Contents}

1. Introduction....................................................

2. Literature review.............................................

a. Sociology of Occupations and Professions..................2

b. Capital and Cultural Intermediaries.......................

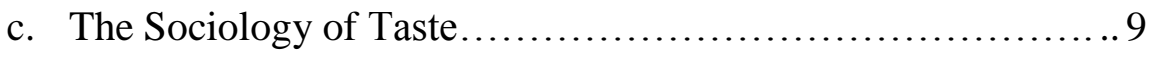

d. Professionalization and Craft Bartending...................12

3. Research Questions...........................................14

4. Methods.........................................................

5. Research Setting \& Participants.................................. 17

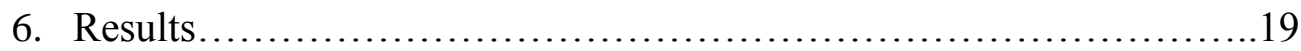

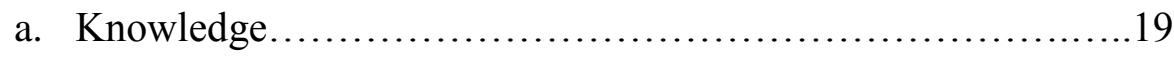

b. Service \& Technical Skills................................23

c. Performance of Being a Professional......................27

7. Discussion.................................................... 33

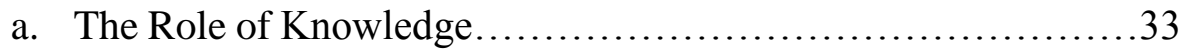

b. Service and Technical Skills.............................. 36

c. Craft Bartenders as Cultural Intermediaries...................39

8. Conclusion................................................. 42

9. References...............................................44

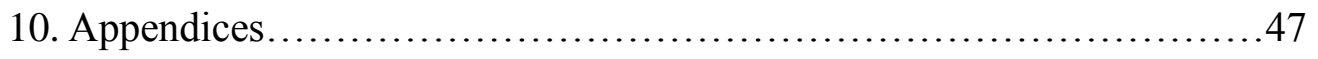

a. Appendix I: Participants..............................47

b. Appendix II: Interview Guides..........................48 


\section{Introduction}

The father of American cocktail bartending, Jeremiah (Jerry) P. Thomas, was a golden name in saloons and hotels alike in the 1800s. He was the first cocktail bartender to write down and publish his recipes and techniques, in an age when recipes were guarded jealously by bartenders. While he is well known in cocktail circles for this publication, he became famous across America for his theatrics (he was fond of fire), opulent dress, and lavish cocktail lounges and barrooms adorned with stained glass, funhouse mirrors, and gold-rimmed cups. Jerry Thomas almost single-handedly pioneered cocktail bartending as a creative and respectable profession that could gather as much money, prestige, and respect as the medical doctors. Indeed, he was often referred to as "Professor" Jerry Thomas (Wondrich, 2007: 14, 27-42). Today, craft bartenders are still creating in cocktail lounges, restaurants, and hotels across the world. However, many people view bartending as unskilled labor, and there has not been a movement to establish a national association of craft bartenders. Despite this, many bartenders follow in Jerry Thomas's footsteps, believing themselves to be professionals worthy of deference and respect.

This study focuses on a small craft cocktail bar and the attending bartenders as a case study of occupational professionalization. The main research questions address how craft bartenders define their profession and their work, and what, in the absence of a formal, accredited standard, defines craft bartenders as professionals when compared to other types of bartenders. While many studies of professionalism focus on accreditations, income, and prestige as hallmarks of professionalism, this project draws on sociological concepts of capital, theories of professionalism, and the field of the sociology of taste to explore the processes that contribute to this type of professional work. 


\section{Literature Review}

Sociology of Occupations and Professions

The sociological subfield encompassing the sociology of work and occupations (WO) addresses a multiplicity of topics. Publications overwhelmingly concern gender (20\%), while others address status mobility, income, unions, inequality in work experience, and labor (Abbott 1993: 190-193). Despite this broad range of topics within the WO literature, the sociology of professions occupies a small and specialized niche, and researchers have different explanations and theories on what truly makes one a "professional".

The classic definition of a profession is, " an occupation (as medicine, law, or teaching) that is not mechanical or agricultural and that requires special education; a type of job that requires special education, training, or skill” (Merriam-Webster, n.d.). However, sociologists often apply other characteristics and standards when defining this type of occupational group. As well as levels of skill and education, researchers also evaluate the standards of professional occupations along continuums of status, prestige, accreditation, income, autonomy, and selfregulation.

The characteristics of occupations and professions vary in several ways, along a continuum that includes the skill required for the work, the autonomy that the workers have in doing their work, and extent of self-regulation within the occupation itself (Brown 1992; Collins 1979; Freund \& McGuire 1995; Larson 1979). Occupations higher up on the continuum are considered more professional than occupations lower on the continuum. Unskilled labor, for example, is just that: unskilled. Occupational groups such as nighttime grocery stockers and day farm laborers have low levels of skill, autonomy, and self-regulation. Semi-skilled and skilled labor, such as electricians, have higher levels of these characteristics: these occupational groups 
require high levels of skill, engage in self-regulation though the formation of trade schools and unions, and although their levels of autonomy are not very high (the customer dictates what needs done in their home or business), the workers still have freedom to choose how the job needs to be done. Occupations that would be considered crafts (such as woodworking, music, and other creative arts) require high levels of skill and have high levels of autonomy; however, their self-regulatory abilities are likely very low, perhaps due to the high levels of autonomy. The variance across consumer's taste impedes the ability to create a monolithic standard for the creative trades (Gronow 1997).

Finally, occupations such as medicine and law score very high on all three occupational characteristics: they require high levels of skill, high levels of autonomy concerning what work they pursue and how they choose to pursue it, and extremely high levels of self-regulation. A multitude of formal, legal, and accredited associations (with the power to exclude or banish members) contribute to this self-regulation, and provides barriers to reaching this level of occupation. Occupations with high amounts of autonomy, self-regulation, and skill are often referred to as professions.

Professions have also been conceptualized as special occupations that function as subcultures. Professional groups often require extensive training, and have informal or implicit codes of conduct and behavior, as well as a sense of occupational solidarity. This sense of solidarity enforces the informal rules governing behavior, acting as a type of social control as well as a boundary between the occupational group and outsiders. The professional group can also confer special privileges or advantages upon its adherents (Jackson 1970: 23-4). For example, passing the Bar Exam allows one the privilege of being able to legally practice law in the US, and becoming a member of The National Lawyers Association allows one to network 
with other members of the group, as well as reap benefits such as sponsorship and the possibility of leadership positions (National Lawyers Association, 2015).

While professions have their own sub-cultures that can confer benefits amongst their members, being permitted within the ranks is a challenge. One way to enter a profession is through the accumulation of education and knowledge. Everett Hughes (1963) defines a "profession" as an occupation that delivers services, and requires a greater deal of practical and theoretical knowledge than comparable types of labor (Hughes 1963: 655). Professionals utilize a broader and deeper understanding of their occupations than comparable workers; for example, a neurosurgeon would be considered a professional because of their expertise in a specialized field of medicine, while a hospital volunteer would not.

Hughes posits that many professionals make a living by assisting, advising, and serving clients. The professional's devotion to mastering a practice, adopting a professional integrity, and becoming familiar with a specialized branch of knowledge leads to a degree of trust in the professionals by their clients. The professional knows better than the client, and so clients place trust in professional workers (Hughes 1963: 656). The phrase "credit emptor" (let the buyer trust) is appropriate here, as the consumer trusts the professional to do their job well (Hughes 1963). In addition, since the average client does not know as much as a professional, clients often defer to the professional when they are unsure. Though few individuals could follow the complex terminology and extensive research that goes into an organ transplant, the patient trusts medical professionals to perform their jobs well during the procedure. While patients may ask for second opinions, they often seek out professionals in the same field for said opinion, further supporting the argument that clients place high levels of trust in professional workers. The 
degree of mastery and depth of knowledge are two characteristics that, in Hughes's opinion, separate skilled professions from other occupations.

It is also interesting to note that Hughes (1963) mentions that professions have methods of gatekeeping in place to sift out potential workers, with professional workers often adopting an active role. This is similar to the idea of self-regulation within professions addressed previously. For example, students studying law or medicine must attend specific schools for several years, and take detailed, comprehensive, and intensive exams. After graduation, many students also must complete secondary forms of training, such as apprenticeships or, more recently, postdoctoral residencies. These filters exclude many individuals from professions, including those without the necessary drive, ability, financial assets, or social standing. These methods of systematic exclusion are types of professional self-regulation, and may contribute to many professions' elite standings.

While Hughes primarily focuses on knowledge, recognition, and separation from similar work as markers of professionalism, he only briefly mentions the role of formal accreditations in relation to professions (Hughes 1963:660-2). However, Randall Collins (1979) also addressed the topic of professionalization in his work on credential societies ${ }^{\Delta}$, and his conceptualization of "professional" differs from Hughes's. Collins perceives professions as varying along a continuum, with an ideal type being derived from the sciences, law, and medicine. For a profession to be 'strong', it must require technical skills that can be taught, and produces results of value. Many of the traditionally strong professions, such as law and medicine, have required credentials that must be acquired by those who wish to work in the professions. He mentions that

\footnotetext{
$\Delta$ Credential societies place an emphasis on certificates and degrees as evidence of an individual's qualification to perform a certain job or attaining social status. For example, having a law degree and passing the Bar Exam are considered the credentials necessary for one to practice law.
} 
professions vary along lines of difficulty in acquiring skill and autonomy (Collins 1979: 132-3). Whether non-professionals can do the work or evaluate it are important factors on this continuum.

Within this standard, occupations such as medicine and law (and their various subfields) are still true professions. However, other workers who claim professionalism under Hughes's standards of knowledge but don't have formal credentials or obscure skills (such as fashion bloggers, musicians, bartenders, and homeopathic healers) would likely be considered low on the professional scale. Credentials provide another form of gatekeeping within professional occupations, and would fit the description of high self-regulation within the group.

This self-regulation also affects the status of professions by limiting who is permitted within the group. By excluding many people from a profession, credentialing can create a shortage of professional workers (Collins 1979). A low number of professionals in a population can lead to elevated status for the professionals, as it implies that their skills and services are not only in demand, but also accessible by a small percentage of the population. The profession's credential requirements also have the power to exclude low-status or otherwise undesirable people from the profession, further enforcing the idea that professionals are few, knowledgeable, high-status, and respectable.

Despite this difference, Collins and Hughes both agree that professionals must be evaluated by their peers. A true profession, notes Collins (1979), is evaluated by its own members and adherents. An occupation that can be easily or effectively evaluated by outsiders has not undergone the process of professionalization, and its workers are not considered professionals. On the 3-part continuum of professions, this method of evaluation is comparable to worker autonomy, and is true of some types of skilled work. Professionals such as electricians, 
though high in worker skill and self-regulation, have less worker autonomy: a client can tell when a job is incomplete or badly done, and may refuse to pay the worker. However, Collins and Hughes's conception of evaluation is relevant to other occupations with high worker autonomy, such as medicine. Since a medical doctor can do everything right and still lose a patient, the question of who can make the call of malpractice become obscure. It may take a medical association or another board of the doctor's peers to decide whether malpractice happened, or whether the patient was beyond help from the beginning. In short, only professionals can be the judge of another professional's work in certain occupations.

This type of worker autonomy, along with the process of accreditation and other forms of self-regulation, leads to the conception of professionals as high-status workers. These workers devote much of their time to improving their practice, acquiring knowledge, and honing their skills. Professionals in established fields, while reaping the rewards of high autonomy, higher skill sets, and high self-regulation, also accumulate various forms of cultural capital, which support and enforce the high status of professions.

\section{Capital and Cultural Intermediaries}

Pierre Bourdieu's concepts of field, habitus, and capital are useful when discussing how status is conferred to individuals, workers, and professions. These concepts all relate to and influence one another. Field refers to a space or place in which social interaction happens, such the field of education, the field of law, and the various occupational fields. It is assumed that all actors on a field are trying to win by accumulating 'points', which take the form of capital (Thomson, 2008). Though fields often overlap and interact, professions have their respective 
fields in which their players (employees) operate. Self-regulation keeps these fields relatively exclusive, as only a small number of agents are in the fields of medicine at any time.

The concept of habitus concerns the why of people's actions, and encompasses attitudes, behaviors, perceptions, and methods of interaction (Maton 2008). While the social world and its various fields affect an individual's habitus, habitus itself affects how an individual perceives, interacts with, and influences the social world. Habitus in the workplace concerns an employees' work practices, habits, and attitudes; it can be influenced and developed by employee training programs, as well as informal tips and tricks that workers learn on the job.

Bourdieu's concept of symbolic capital refers to social mobility beyond purely economic means, as well as social relationships within systems of exchange (Moore 2008). For this research's purposes, I will focus primarily on cultural capital ${ }^{\Delta}$ as it pertains to professional work. This type of capital consists of the skills, education, and knowledge that a person acquires and possesses, as well as one's tastes, preferences, and lifestyle. An individual who is educated, highly skilled, or possesses certain types of tastes and preferences accumulates a higher amount of cultural capital compared to the average individual. In the workplace, cultural capital can take the form of employee skill, knowledge, and mastery. A supervisor, for example, usually has more cultural capital than the employees who work under them, as they are assumed to have more knowledge, training, and skill.

These three concepts interact to influence all aspects of the work experience. The occupational field may dictate the rules, norms, and ways to accumulate certain types of capital, and thus influence the worker's habitus. In return, the habitus of the workers may lead to the

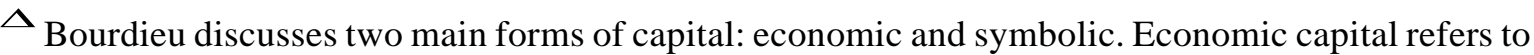
financial assets and exchanges. The second category is used to categorize forms of capital that do not take the form of financial exchange. Symbolic capital includes cultural capital, linguistic capital, scientific capital, literary capital, and cultural capital.
} 
development of new norms and rules, which could affect the occupational field itself. In this way, these concepts continuously influence one another.

Individuals that possess high cultural capital can also act as cultural intermediaries. A cultural intermediary is an individual that acts as a middleman between producers and the consumers of cultural or symbolic goods and services (Bourdieu 1984: 354-65). Cultural intermediaries are primarily employed in occupations that concern cultural production, such as music, fashion, and other types of media (1984:359). A cultural intermediary possesses high cultural capital, as it is their knowledge and skill that allows them to speak with authority on the quality and worth of goods. By adding or subtracting value, cultural intermediaries have the power to shape tastes, preferences, and the opinions of consumers (Bourdieu 1986: 359-360).

Professionals can acquire cultural capital in several ways: acquiring exclusive knowledge (through education, training, and/or accreditation), excluding undesirable workers (selfregulation), and possessing high autonomy on the job that delegitimizes outsider criticism. Thus, professionals who accumulate high levels of cultural capital act as particularly effective cultural intermediaries. The trust that clients place in professionals, along with the elevated status of professional occupations and their high cultural capital, lends the professional worker enough authority to influence the tastes of consumers. Even within occupations and professions that have low self-regulation and few credentials, clients and consumers can judge according to a professional's cultural capital, composed of their skills and knowledge. More importantly, consumers also make judgements about professionals and their services based on taste.

The Sociology of Taste 
The concept of taste in sociology refers to preferences in food, drink, fashion, and lifestyle. The sociology of taste is a small subfield that began with Kant's writings on the location and judgement of taste (Kant [1790] 1952). From there, Veblen ([1899] 2005) and Simmel ([1904] 1957) investigated taste as a mechanism of stratification between different social and economic classes. This line of work was primarily concerned with how economic capital influenced consumer taste: the high-class, respectable preferences in any given society are usually the tastes and preferences of the ruling or highest social class of that time (Bell 1992: 113). The ruling classes in many societies are also the wealthiest classes, so 'good taste' translates into a symbol of high status. For example, a man wearing a suit commonly thought to be tasteful is thought to be wealthy and successful. The suit itself, though only stitches and cloth, is used as symbol of high-status, wealth, respectability, and good taste. Status symbols such as this are considered desirable precisely because only a small, wealthy, high-status portion of the population can afford them. Those who cannot afford the markers of high taste are excluded, as purchase of these goods is a marker of membership in a group (Gronow 1997: 33; Goffman 1951). Taste, in this classic sense, is largely conceptualized as material deprivation: poor people cannot afford what rich people have, and thus do not have it.

This explanation for the taste of consumers, while partially true, neglects the other characteristics of taste as a status symbol between classes. Bourdieu found that different social classes did not always strive for the same standards. Instead, upper and lower classes sometimes have different tastes (Bourdieu \& Passeron 1979). Fashion is a perfect example of this. While a classic suit may be considered desirable by all classes, expensive, avant-garde clothing is not. Some high-priced items, though symbolizing economic status, may not accurately reflect society's taste: lower classes may not want to purchase expensive clothing because they simply 
don't like it. These differences are most stark in situations when consumers from a low-class background suddenly become financially successful. While those raised within a high socioeconomic class may purchase a sleek, classic car (such as a Jaguar), a 'new money' consumer may spend the same amount of money on a loud truck with spinning rims and a garish paint job. While both consumers spent the same amount of money, it is apparent that they have vastly different tastes; the old-money consumer likely thinks that the new-money consumer has bad taste, regardless of their financial capital. However, though the method of differentiation may vary, the observation that different classes have different tastes is still valid.

These differences can translate into social and cultural status and power in society (Woodward and Emmison 2001), and can have a marked effect on certain professions. Several occupations are located squarely within the field of taste, such as fashion design, interior decoration, bartending, and the culinary arts, and these workers act as cultural intermediaries. Cultural intermediaries must have a grasp of consumer tastes to do their job effectively. Though taste may differ between individuals and classes, it is still important as a status symbol.

While lower class consumers may have different tastes than their counterparts, professionals employed in occupations that cater to high-class tastes must still cater to that taste. It follows that those with expertise in higher-class taste have historically been associated with a high social class, even if the workers themselves do not come from said class (Gronow 1997: 28). This specialized knowledge skill set serves to separate the high-class professional from both their clientele and other occupations that do similar work ${ }^{\nabla}$ but lack the familiarity with highstatus goods. By associating themselves with these high-status goods, professionals within these

\footnotetext{
$\checkmark$ For example, a fashion designer that mass-produces cheap clothes for lower-class consumers would not be afforded the same status, respect, and deference as a designer that caters to the wealthy class.
} 
fields often adopt the associated high class status. This status attainment acts as both a skill and a type of self-regulation that distances professionals from other types of workers, furthermore cementing their professional status.

\section{Professionalization and Craft Bartending}

Bartending is an occupation deeply rooted within the field of taste, and different types of bartenders cater to different types of tastes. Some bartenders work at sports bars and dive bars; others, however, are employed at high class, expensive cocktail lounges. This research will focus on the craft, or cocktail, bartender ${ }^{\Delta}$, for though they lack self-regulation in the form of formal accreditation, research suggests that they may possess many other markers of professionalism (Ocejo 2011; 2012; Wondrich 2007).

Certain occupations within the service industry are undergoing a process of occupational transformation. Many jobs have begun to accumulate additional skills, certifications, and cultural capital, and are thus transforming into skilled professions. Richard Ocejo (2011) focused on cocktail bartenders in New York City to elucidate the mechanisms by which service workers undergo changes that lead to them becoming professionals. His research attempts to explain this occupational change from a low-status service job to a high-status profession, using cocktail bartenders as a case in conjunction with Florida's theory of the Creative Class (see Florida 2002). Ocejo discovered that craft bartenders believe themselves to be professionals because of their extensive knowledge of spirits, history, and techniques, as well as their devotion to their work.

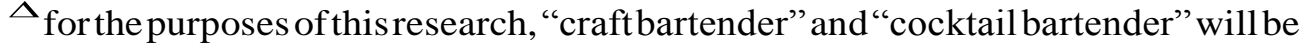
used interchangeably.
} 
A second study by Ocejo (2012) examined the position of a craft bartender as a cultural intermediary. Cocktail bartenders become cultural intermediaries when they influence their guests' taste by offering only particular cocktails and spirits. Bartenders are in a unique position to influence their guests' taste, as they literally stand between the guest and the alcohol. One marker of professionalism occurs when a craft bartender often possesses enough authority that his suggestions and opinions are rarely questioned by the guest. If a craft bartender is a knowledgeable and skilled professional, then they should know better than the consumer and thus are deferred to when it comes to questions about the quality, quantity, or appropriateness of spirits. They may also be deferred to as a knowledge basis when the purpose, professionalism, or legitimacy of their field is concerned.

In order for an occupation to be considered a profession, several factors must be taken into consideration. A profession demands a high amount of skill, has high autonomy, and high levels of self-regulation. In addition, professional workers acquire large volumes of specialized knowledge. Professionals within fields of taste and culture also must be adept at recognizing and reproducing high-status tastes and style, and adopt the high statuses associated with their products. For craft bartenders, their profession requires strict attention to detail, independent thinking skills, and an extensive knowledge of certain crafting practices and high-quality ingredients. The increased cultural capital that comes with increased skill also makes the craft bartender a candidate for being a cultural intermediary and a professional.

For the purposes of this study, the concept of professionalization will be explored from the viewpoint of the craft bartenders. First-hand accounts will be analyzed with an eye towards the question of whether craft bartending possesses the necessary high skill, high autonomy, and 
high self-regulation will be investigated, as well as how habitus, capital, and taste influences these factors.

\section{Research Questions}

My research questions are concerned primarily with the professionalization of cocktail bartending.

1. Building upon Ocejo's finding that craft bartenders differentiate themselves from their contemporaries and often describe themselves as professionals, I ask the following...

a. Do craft bartenders meet the standards of professionalism (high skill, autonomy, and self-regulation)?

b. How do craft bartenders distinguish themselves as professionals, and as different from other bartenders?

c. As professionals, how are they acting as cultural intermediaries?

\section{Methods}

The first method employed in this study was ethnographic observation of the restaurant and employees as they interacted in the workplace. Observation consisted of sitting at the bar for at least an hour at a time, on rotating days and times. The observational period started in September 2016 and continued until the end of March 2017. A total of fifteen (15) observational periods were completed, ranging from an hour to nearly five hours, for a total of 38 hours of observation. The basic housekeeping duties of the employees, the step-by-step process of crafting drinks, and the interactions between all employees and guests were the subjects of study during these observation periods. Given the relatively informal atmosphere of bars and my acquaintance with the employees, my presence only minimally affected the site. Employees 
continued to perform their jobs as normal, largely treating me as any other guest at the bar. The only way in which my presence possibly influenced the site was the fact that I usually sat at the far end of the bar, where servers often interacted with bartenders, so their interaction may have been lessened by the presence of an active observer.

Coupled with observation, interviews were the primary form of data collection for this research. The interviews were semi-structured, focusing on the nuances of the requirements of craft bartending while allowing space for topics to emerge organically. This had two purposes: keeping the conversations casual, natural, and comfortable, and allowing the respondents to discuss aspects of the profession that may not have been an initial focus of this research (Weiss 1994: 66-78). In the event of an unknown topic, I let the respondent speak at length, unless the topic was wholly unrelated to the study. Among the topics addressed were the bartender's background, training, skill set, knowledge of craft bartending history, knowledge of drinks/spirits/ingredients, their views on the profession as a whole, if they believe themselves to be professionals, and views on Copper \& Co.'s niche in Hill City. Interview guides for bartenders, owners, and servers are included in the appendix.

Respondents consisted of the bartenders and servers (8 respondents) employed at Copper\&Co, as well as the two owners. At this establishment, a small number of bartenders often take on managerial and/or serving duties and as well, so their interviews are tailored to reflect the difference in job responsibilities. The servers employed at Copper\&Co. were interviewed because although servers fill a different role in cocktail bars than bartenders, they engage in extensive interaction with both the bartenders and the guests. The servers' perspectives added valuable insights in this study. Two servers resigned during the course of this study; one agreed to be interviewed post-resignation. One server did not consent to be interviewed. 
The two data sets (observation and interviews) were compared for any inconsistencies. In short, I wanted to see if what is said in the interviews were actually played out in the workplace. For example, an inconsistency would be a bartender stating in an interview that they take the utmost pride in being a professional, but arrives to work late, hungover, and with stained clothing. The content of the interviews, however, was on par with what was observed. The interviews varied in length, the shortest being about 28 minutes and the longest running 75 minutes.

Participants were fully informed that their interviews would recorded and transcribed for the purposes of this study. They were informed that they had the option of skipping or refusing to answer any question they wish, and to end the interview at any time. Four interviews were conducted in the respondent's home, two were conducted at the establishment, two were conducted at a local café, and two were conducted in the interviewers' home.

Codes for interviews were largely allowed to emerge organically through the interview process (Weiss 1994: 155-6; Glaser 1992: 189-90) However, the interview guide was utilized to ensure that certain topics were addressed. Among the topics that were addressed during interviews (in no particular order) were the bartender's crafting background, skill set and level, how they view other bartenders, and their views on their own professionalism. This set of preestablished codes were also utilized to assist in categorizing data and behaviors noticed during the periods of observation. Although the codes that emerged from observation were not identical to the codes used in the interview guide, they addressed roughly the same scope of behaviors. However, the codes for the observational periods could not, for obvious reasons, include the thought processes of the employees and their views on their work. 


\section{Research Setting \& Participants}

Copper\& Co., is a cocktail and tapas bar in Hill City, a college town in the northeastern US. The atmosphere is more formal than a typical college bar. There are lit candles and polished silverware laid on every table. In addition, the menu is primarily composed of various tapas (small plates) such as scallops and charcuterie. More obscure spirits, such as Green Chartreuse and Cachaça, grace the cocktail menu. The kitchen does not have a deep fryer, and there is no formal children's menu. It is a small establishment, with only ten tables and a small kitchen that is visible from the dining room.

The small size of Copper \& Co., coupled with low lights, an impressive bar, and five crystal chandeliers, contributes to the atmosphere. The bar is speckled marble, and the shelves are carved of dark wood. The chandeliers cast a golden light that is enhanced by the small white candles on every table and taller candles between bottles of spirits. The cleanliness and orderliness of the entire restaurant gives the impression that this is an establishment that emphasizes quality of service. Calls inquiring if there is a dress code are not uncommon, and the bar regulars include lawyers, accountants, university professors, and scientists from the local engineering complex.

This bar was selected as a site due to its importance to the food and beverage scene in Hill City. In addition, Copper\& Co. is the only establishment that places a heavy emphasis on its cocktail program. While Hill City offers a variety of dining establishments, such as fine dining, wine bars, and gastropubs, Copper\& Co. proudly specializes in classic (pre-Prohibition) and prohibition-era cocktails, as well as locally-produced craft beers.

\section{Respondents}


Tim and Chuck are the owners of Copper \& Co. They met in college and reunited several years ago with plans to open a local establishment to stimulate downtown Hill City's food scene. At least one of them is in the restaurant every day, assisting employees and making sure that everything runs smoothly.

Vladimir (Vlad), 36, is the head server at Copper \& Co., as well as the resident Sommelier ${ }^{\wedge}$. He has been a server for over 18 years and has bartended periodically during that time. His employment history includes presiding as a banquet captain at a French bistro as well as the resident Sommelier/ head server at a French steakhouse in Las Vegas.

Johnny Utah, 29, is the bar manager. He has been a bartender for ten years. He started out at a local martini bar called Day’s Bar, and started bartending at Copper almost as soon as it opened for business.

Gyda, 22, has worked at Copper \& Co. for about two years. She spent a few months serving before moving to bartending. Her restaurant experience before her move to Hill City included chain restaurants such as Red Robin, where she bartended as well as waited tables.

Sampson (Sam), 21, is a law student at Hill City University, and primarily works weekends. He formerly was employed as head server and bartender at a local café. He has worked at Copper \& Co. for roughly eight months, primarily as a bartender.

Amos, 23, is a bartender and server that has worked at Copper for about eight months. His previous experience in the restaurant business was in the back of house (kitchen/dish). Copper is his first front of house job. He is a student at the University.

\footnotetext{
$\Delta$ A Sommelier is an accredited wine steward who is responsible for not only knowing about wines, but is also required to be familiar with a range of spirits, beer, and even cigars. There are five levels within the Guild of Sommeliers, with Master Sommelier being the highest possible accreditation. Vlad passed his Level 1 Sommelier Exam in November 2014, and advanced to Certified Sommelier in August 2016.
} 
Alice, 22, is a server who has worked at Copper for about a year and a half. It is her first serious (steady) job waiting tables. She is also a student at the University.

Annie, 22, is a former employee who resigned during the study but still consented to be interviewed. She previously worked at a local dining establishment in her hometown, and was employed at Copper for almost two years. She resigned for various reasons, citing not being moved to the bar and not enjoying her job as much as she used to. She is a student at the University.

Emilia, 28, is a server at Copper \& Co. She has worked sporadically at several local gastropubs (including Copper \& Co.) for the past 3 years and is currently training to take on management duties.

\section{Results}

Although their answers are phrased somewhat differently, many respondents share very similar mindsets when discussing the nuances of their job. The questions, "what makes a professional/good bartender? What do you think is important?" elicited central insights into how cocktail bartenders view their profession. The themes that emerged most strongly are:

1. Possessing a deep knowledge of drinks, liquors, liquors, \& cocktailing.

2. Possessing service \& technical skill

3. Believing in the performance aspect of professionalism

Each of these are addressed in full in the sections below.

\section{Knowledge}


According to interviewees, a trait that sets cocktail bartenders apart from their peers is their mastery of a particular type of knowledge. Respondents insisted that extensive and comprehensive knowledge of their trade is a necessary requirement of a cocktail bartender, and employees possess a certain amount of capital based on their expertise. Even the servers at Copper \& Co. are required to possess a portion of this knowledge, and part of a server's training involves verbal 'pop quizzes' by the head server to assess familiarity with the menu. This expectation that employees should be familiar with obscure and high-class menu items enforces a stratification system based on the amount of capital individuals possess (Gronow 1997: 33-39).

Being able to craft a good, balanced drink is an essential trait of a cocktail bartender. Amos, when asked about his favorite professional bartenders, mentioned his coworkers. Their extensive knowledge, he mentioned, is what makes them professional.

“... I think as far as Johnny and Gyda's ability to just come up with drinks, to know all the flavors, the different liquors, to know where they're from, you know, they know the procedures, the traditional procedures, just... they're definitely professional, I think. About the whole thing" (Amos).

A great example of this knowledge at work is when a guest sits at the bar and doesn't know exactly what they want, and asks the bartender for a recommendation. The resulting verbal interaction usually proceeds like so:

"Hi, welcome to Copper \& Co.l What can I get started for you?"

"Hey, I'm not sure. Nothing on the menu is really speaking to me."

"Well, what do you like? Something sweet, something bitter, something with gin, something with whiskey...?"

"Well, I like bitter drinks, and I like rye whiskey."

"Well, how about an Old-Fashioned with rye? Or we could do a Manhattan with Pikesville Rye, that's 100 proof."

"That sounds excellent, I'll try that, thank you." 
I observed three or four conversations like this going on at Copper every evening, such as an older gentleman who simply wanted something like a Manhattan but with gin, and was guided to The Hearst. Knowing flavor profiles and acceptable pairings is required of bartenders, and they're expected to know enough about each liquor to be able to assist every guest.

Upon occasion, other bar patrons become involved. One Tuesday evening, around 9pm, an older gentleman named Jay stepped in and helped another guest by offering his own opinions on scotch. Even then, Jay deferred to the bartender, asking Johnny to 'back up' his opinions: “The Arbelour is smoother than the Laphroig Triple Wood, isn't it, Utah?” This deference seems to have occurred because Johnny, as the bartender, is more knowledgeable about the flavor profiles than his bar guests. This supports Hughes' (1963) idea that a characteristic of professional status is the deference shown to professionals when clients are unsure.

This specific type of knowledge extends to the dinner menu and wine list. When asked about people's reactions to Copper, Amos mentioned that people often were surprised and even confused when reading the dinner menu.

"Some people are fascinated with it, and some people are thinking, you know, cuz we're in Hill City, where's the hamburger and the french fries?... people don't like the price sometimes, you can see it... or the portion size. Cuz they don't know what tapas is. A lot of times. They are generally... very curious about the cocktails.

[INTERVIEWER] and you have to know how to answer all of that?

Well you do have to know how to answer that, that's the hard part. Or even what's in it. Like... what's Pernod?" (Amos).

Knowledge in the cocktail industry is a status symbol, a mark of status and pride amongst the bartenders. Aside from the extensive cocktail lists, bartenders must also be familiar with wine: the wines at Copper \& Co. include bottles from France, Italy, Spain, Germany, and South Africa. All front-of-house staff are expected to be familiar with the wine list, as all servers and 
bartenders can expect to serve a guest that orders wine. In addition, there are many spirits that are not on any formal list, and the bartenders must be familiar with these as well.

"[INTERVIEWER]... and you as the bartender, the server, you have to know how to answer those questions, you have to be pretty knowledgeable...

Right, you do have to be, and I felt the pressure many times on things that I didn't know. You know, what kind of vodkas do we have? What scotches do we have?...I mean, I'm glad we have a whiskey list, but we don't have a list for gins, we don't have a list for vodka, don't have a list for tequila, so you get a lot of those random questions... maybe you don't drink it, I don't drink all the vodkas or anything like that. But you still need to know, and the pressure's definitely on, definitely there...

Another thing is like, the wine. We have a lot of wine, and we don't try all the wine... I mean a lot of them are by the bottle, so that's a hard one to know. Or people say, when I'm serving them, or yeah. Any kind of bartending or serving, 'I'll take the Lebanese wine'... so you almost need to know all three portions. Distributor, like the winery, where is it located, and what is the name? what kind of wine is it? Is it a Cabernet, Bordeaux, whatever" (Amos).

Other bartenders echoed the above sentiments. Gyda has taken an active role in educating herself on cocktails and liquors. In the beginning, learning the classics absorbed her attention.

Soon after, she began to accumulate her own knowledge in earnest:

"I had to learn classics, which there's a ton of, and I had to learn the house cocktails... but as far as learning about all the spirits and everything, where they come from, I just research it... like when we get something in I try it, and I want to know where it came from or why it gets it flavor or why it is what it is... I read a lot of bar books. Instagram, also, talking with other bartenders all over the world, seeing their pages and what they're putting out" (Gyda).

Accumulating expertise is a very real challenge to cocktail bartenders. Aside from the fact that being more knowledgeable makes one better at the job, knowledge serves as a way of ranking and covertly judging other bartenders in the industry, and so acts as a method of selfregulation within the profession. Gyda, Vlad, and Johnny all admitted to testing bartenders when they venture to other bars to see if they're knowledgeable, skilled, and thus professional. This 
self-regulation functions as a type of boundary maintenance: "real" bartenders within the

profession possess a certain type of knowledge and skill.

"Like, the Last Word...which, we've talked about that, off the record, its equal parts Green Chartreuse, lime, Luxardo, which is a maraschino liqueur, and a London gin, a dry gin. Equal parts, shake it strain it... to me, its equal parts, it should be an easy drink to be made" (Vlad, emphasis added)

"But if I go to a bar, I obviously judge out like where I'm at... Like I know if I go to a cocktail bar, they should be able to make classic cocktails, because that's what every bartender should be able to do in this industry, anyway. So I usually order an Old Fashioned, a cocktail that I judge bartenders on heavily, because a lot of bartenders will use like different ingredients for it and they'll like shake it instead of stir, and it's really watered down and just not a good cocktail. And a Vieux Carre is the other one that I like. I ask if they know how to make a Vieux Carre, and they do, then I'm like OK, I know that I'm in a safe place to order cocktails" (Gyda, emphasis added).

If the resident bartender creates these classic cocktails the right way, then they are 'real' cocktail bartenders, and business can go on as usual. This knowledge of classic cocktails covers not only what goes into Old Fashioneds, Vieux Carres, and Last Words, but the proper way to craft these drinks. This discretion and knowledge sets cocktail bartenders apart from 'volume' bartenders that work at nightclubs or sports bars, thereby regulating who is and is not in the profession. In their opinion, this boundary makes craft bartenders professionals.

Service and Technical Skill

Another characteristic that craft bartenders use to distinguish themselves from other types of bartenders is a mastery of technical skills behind the bar. While the performative aspects of bartending can be considered a skill, the characteristic referred to as "technical skill" by respondents is more in the ballpark of craft production (Ocejo 2011) $)^{\nabla}$. The skill of craft

\footnotetext{
$\checkmark$ craft production refers to, "the making of specialized products by hand using specific raw materials and artisanal techniques” (Ocejo 2011: 181).
} 
production is also a marked point of pride to cocktail bartenders, and involves all three professional components: skill, autonomy, and self-regulation. Bartenders decide among themselves how good a craft cocktail is constructed, and make judgements based on that decision. Knowing which drinks should be shaken is important, but being able to properly shake a drink is a technical skill learned through experience. The methods of crafting a flag ${ }^{\Delta}$ and getting a good head on different beers are learned, and are just as essential to the craft bartender as their knowledge base. In addition, craft bartenders are also able to adopt a high status because of their craft production, as the consumers of crafted items are usually consumers with high cultural, social, and economic capital (Johnston \& Baumann 2007).

Several respondents also had an interesting secondary response to the 'good bartender' question. They mentioned traits such as multitasking, speed, and courtesy as being essential. Amos, whose previous experience at Copper was serving, was taken aback by the energy and complex movements that take place behind the bar.

"Because there's a lot of things going on around you, you're making drinks, you got the servers asking for refills on things, like can you hand me this, can you give me some cream, you got the guest in front of you and they're eating, or they finished eating, they want dessert now, but they're six tickets behind you, and figuring out in what order I'm gonna do this, when I'm gonna hand these people menus that just walked in, and give them water, take their order." (Amos).

During a busy Friday evening, the smoothness and intensity of the bar is easy to see. The bartenders talk to their guests and each other, but there is always at least one bartender 'in the well', whose sole task is to build drinks for the servers. Despite the lightning-pace of the bartenders, each drink still received its due attention. Being able to keep a cool head under

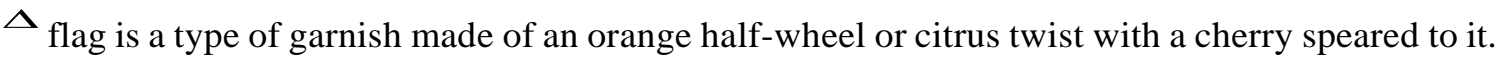
Flags are used to garnish certain drinks, such as sours, Old-Fashioneds, and Vieux Carres.
} 
pressure is something that bartenders take pride in, and subsequently, expect from their coworkers.

"I'd like to say attention to detail is important because those little intricacies of two sugar cubes soaked in five bitters, then doing the orange twist, muddling, stirring with bourbon, dropping the ice cube and stirring again... the attention to detail is important... my detail is in build of a drink. And the proper rinsing of a martini glass with vermouth. Or properly spraying, or doing an absinthe rinse, properly shaking... like if you're cutting corners, you're lazy. And I don't wanna see something that's lazy" (Vlad).

Each bartender expects their fellows behind the bar to put in full effort every shift. One evening, Gyda mixed and poured a drink for a guest, opened a bottle of wine and poured it into a decanter for another guest, set out a place setting in front of me, and filled a Coke for a server's ticket, in one fluid motion. Bartenders expect their coworkers to be able to keep up, and enforce these expectations via methods of social control. Employees that are slower behind the bar may be verbally reprimanded, and are usually not scheduled on busy nights, for example, and so make less money. This informal self-regulation further serves as a method of stratification within craft bartenders.

Respondents also took pains to differentiate cocktail bartenders from bartenders at 'volume bars'. A volume bar, according to respondents, is a nightclub or sports bar type of establishment which puts an emphasis on getting as many drinks out as quickly as possible. Respondents emphasized an important distinction between the two 'types' of bartenders: a cocktail bartender focuses on the quality of service and pays close attention to their craft, while bartenders at volume bars focus almost entirely on speed.

"The volume bar... the name of it says it in itself. You're after volume. You don't really care about craftsmanship of how your vodka tonic is made, you wanna see how fast you can get 10 vodka tonics out to your guests. You have a barmaid, basically little containers of cherries and limes and lemons, all pre-sliced, all pre-everything, so boom boom boom volume volume volume. That's not... that's not what Copper is. You know, you go there, you pay 8,9,10 dollars per cocktail to have it handcrafted in front of you. Not to have it slung in 20 seconds ... in a plastic cup, slopped everywhere..." (Vlad). 
Volume bartenders also possess a different type of knowledge than craft bartenders. One respondent emphasized that the main difference was in the types of knowledge that each bartender was familiar with.

"I don't think a lot of people know how to do it (craft bartending). I think they could do it, obviously, but I don't think, if I said hey make me an Old Fashioned, I don't think even half of those bartenders would know what to do. But I mean, if someone came up to me and said hey, make me a Green Tea shot, I would just stare blankly at their face because I have no fucking clue... those places, different places, they know how to make a shit ton of shots that I have no idea how to make" (Amos).

The unfamiliarity of certain drinks to the cocktail bartender points to another characteristic of the craft industry: their expansive knowledge has a limit. Although craft bartenders possess knowledge of classic cocktails and obscure spirits, other drinks are unfamiliar. Since craft bartenders take pains to differentiate themselves from other bartenders, it make s sense that they would possess a different knowledge set. They are not familiar with 'party' drinks because it is not relevant to their jobs, and the lower status associated with these types of drinks is a threat to the craft bartender's claim to high-status knowledge. This distinction is important, as high class tastes are traditionally associated with higher social status, and thus higher capital (Gronow 1997).

The ability to multitask and the skill set specific to the cocktail bartender are traits that respondents highlighted as extremely important. A bartender who does not possess the right type of skills seems to be excluded. Evaluation though expertise, skill, and knowledge seems to be acting as an informal method of self-regulation within the profession. However, part of being a professional is acting like one, and the performance of professionalism is the essential third piece to this puzzle. 
The Performance of Being a Professional

All respondents placed an emphasis on the professionalism that is encouraged within the establishment and the employees. Professionalism, as the respondents defined it, is a conglomeration of attributes and behaviors. It merges themes of elitism and obscure knowledge with themes of formality, high-class knowledge, hospitality, and attentiveness. Their conception of professionalism also touches on themes of exclusion and differentiation from other types of service work.

These attributes of professionalism are enforced and upheld by formal training and informal social norms that are encouraged by both management and fellow employees. Consequently, I found that the behavior and demeanors of the employees are the cornerstones upon which the professionalism of the establishment is built. Being a professional cannot be reduced to only a knowledge base; one must also embody the idea of a professional. For example, t-shirts are not permitted: men wear button down shirts with a vest and bow tie, and women are required to wear black ensembles. It became evident that style of dress contributes to the performance of professionalism:

“...carrying yourself like a professional. Properly having a tie, tied correctly. A clean, pressed shirt. As clean as possible vest if you haven't washed it. Clean as possible apron... Deion Sanders has a quote: if you dress good, you feel good; if you feel good, you play good; if you play good, you win." (Vlad)

"First and foremost, it's my... the appearance I have to have, the upkeep, to maintain... versus theirs, you know. You go to Parrots, dudes in just a t shirt and some jeans, whatever, you go to the sports bar and the girl always has to wear no pants, or whatever. I guess its... I guess it's the clothes to match the customer, I guess." (Amos)

This emphasis on appearance also surfaced when discussing potential hires. Although none of the employees believed they had sole power in hiring decisions, they did believe that their opinions mattered to the owners. Factors that persistently came up in hiring decisions were 
an applicant's demeanor, style of dress, and resume. A subpar resume is a strike against an applicant, and understandably so; however, being underdressed for the interview is also considered a mortal sin in an industry built on appearances and performances.

"Now I've been handed a resume once, looked at it, and immediately crumpled it up and threw it in the garbage."

[INTERVIEWER] I might have been there for that, actually.

"Because this guy came in, in a scrubby $t$ shirt, out-of-date resume, two different fonts. If he cared about his job, he would care about his resume, because that's a statement of who you are. So by you telling me that you don't even have the care to update it, and the care to like, unify the font, what makes me think you're gonna care to put Aperol in a drink or Campari?" (Vlad)

During his response to the hiring questions, Vlad mentioned the old “don't judge a book by its cover" adage: he insisted that oftentimes, the cover is all you have. As demonstrated above, the way one presents oneself can be a deciding factor in if an individual gets hired. Individuals who don't put forth adequate effort in their job search are not perceived as willing or able to meet the standards of the establishment. This is a conscious form of informal social control that acts as a method of self-regulation within the industry: excluding certain types of people serves to keep the profession pure.

Another factor that plays into the performance of professionalism is language. At Copper, employees are discouraged from using casual language and are encouraged to adopt a more formal, hospitable demeanor. During interviews, respondents avoided (to the point of correcting themselves) calling people who frequented the bar "customers"; they were referred to as "guests". The use of the word "guys" is actively discouraged; the plural alternative is 'ladies' and 'gentlemen'. This word choice conveys high status to both the guests and employees via formal language. In addition, formal verbal language goes hand-in-hand with formal body language. Servers and bartenders alike can be observed with attentive postures when working with guests: 
standing straight, steady eye contact, and rapt expressions. When Annie, a server, was asked how her experience at Copper differed from her experience at other restaurants, she replied,

"Completely the quality of service, or just like the importance on precision and care and just general thoughtfulness... I thought it was so overwhelming because they would say that you can't say 'guys'. You need to be really aware of your body posture. Things I would never even consider before..." (Annie)

She also mentioned that employees must maintain a calm attitude at all times, especially when things go wrong. When mistakes happen, keeping a calm demeanor is essential to the level of service that is the standard in Copper \& Co. Servers and bartenders are encouraged to be, “...professional and crisp and clean and straightforward as possible” (Annie). Emotional outbursts when a mistake is made are not tolerated.

“...it's high action, high intensity. But when we get to table side, -whooshprofessional. You go back in the dish pit, you wanna curse at something, you wanna throw an ice cube at a sink, do something, let that anger out, do it behind the scenes" (Vlad).

During one of my observational periods, I noticed conflict between several employees. A misunderstanding between the back of house and the front of house employees escalated to the point where a dishwasher walked out of the restaurant, presumably quitting. However, I am confident that the dinner guests didn't notice the conflict. Despite the discomfort at the server station and in the dishroom, conversations at the bar continued as normal, and servers kept a cool and confident demeanor at their tables. What Vlad said in the above quote resonates with that I observed: drama and conflict happens behind closed doors or in isolated corners, and never makes it to the guests enjoying dinner or a drink at the bar. By maintaining a high level of selfcontrol and regulating their emotions in order to present a friendly and relaxed appearance, the professional staff at Copper continues to embody their idea of professionalism. This conscious 
management of the front stage is essential for the performance of professionalism: never let the audience peek behind the curtain (Goffman 1956).

The performance of professionalism extends past formal language and dress, affecting the attitudes that the employees have towards providing an elevated level of service. Several respondents mentioned that they take pride in their jobs and that this professional integrity affected their work. Respondents spoke at length about the extra steps they take to provide guests with the most hospitable and courteous experience they can possibly provide. They expressed that they would not serve a product that they didn't stand behind and would consume themselves.

“...you want to make this person feel at home and comfortable and want to come back. You want them to like what we're about, because I'm proud of the company I work for, I'm proud to work for Tim and Chuck. And you want the guest to feel that. At some other corporate restaurant ... I just don't care to work for big corporations like that. That's not what I stand for ... you're not as proud of the product you're putting out because it's a spiked lemonade, or you're selling food that comes from a microwave or a fryer. It's not something you're proud of"' (Gyda).

“...I want to believe, I can't talk out of my ass and be really excited about something when I know it's going to be a frozen product that's fried and served...covered in sauce, yeah, exactly." (Annie)

Respondents also mentioned the pride they have in not only performing their jobs, but constantly working to become better. Bartenders expressed that they enjoy their work and take great pride in what they do. Their previous experience in the service and hospitality occupations actively shape their perceptions and practices at Copper. Though Gyda enjoys her job, she expressed a wish to work at a more metropolitan bar to improve her skills and knowledge base. Indeed, when asked if she considered herself a professional, she said that she is a professional only within the context of Hill City. Compared to 'other' bartenders in larger cities, she is not a professional on their level. She feels that she would be "annihilated" by their knowledge, as more urban cocktail bartenders have more access to ingredients and techniques due to their 
metropolitan location and larger consumer base. Metropolitan craft bartenders also have increased access to rare or obscure ingredients, and so more autonomy in how they perform their jobs. This seems to support the idea of professionalism being a function of knowledge and skill in cocktail bartending. In this case, professionalism acts as a form of status between craft bartenders: more metropolitan bartenders are considered more professional than a craft bartender in a college town like Hill City.

Johnny Utah, the beverage manager, has also been at Copper since its opening days. He started bartending at a local establishment, Day’s Bar, that specializes in colorful martinis and frozen drinks. At Copper, he enjoys crafting classic cocktails, as well as creating his own (including his namesake, the Johnny Utah). When discussing what differentiates Copper from his previous bar job, he highlighted the quality and composition of the drinks: unlike Day's, Copper utilizes ingredients such as fresh fruit juice and herbs in their cocktails. Whether bartending or managing, he maintains a formal yet hospitable persona. Indeed, his uniform of a crisp white shirt, dark grey vest, and a bow tie cuts a very genteel profile against the dark wooden shelves behind him. Utah takes great pains to not only look the part, but perform the part of a professional cocktail bartender.

A testament to the sense of professional integrity present in the Copper bartenders can be observed in their dedication to juicing a basket of fruit instead of using store-bought, and trimming fresh mint and rosemary sprigs before every shift. The refined display of fresh ingredients and bow-tied bartenders plays a part in maintaining the bartender's stage (Goffman 1956) and is also a form of self-regulation: while a barmaid ${ }^{\Delta}$ may be present at a volume bar, the

\footnotetext{
$\Delta$ a barmaid is a plastic, compartmentalized container often found on bars. Its compartments are filled with pre-sliced fruit and other garnishes. It often has a clear plastic lid that flips out of the way so bartenders can quickly garnish their drinks.
} 
garnishes at Copper are fresh herb sprigs, authentic black cherries, and fresh citrus twists.

Bartenders who use pre-sliced (or otherwise not fresh) ingredients are not considered within the same class as craft bartenders.

The performative aspects of professionalism extend to off-the-clock behavior as well. There multitude of ways in which bartenders can add to their knowledge affects their job performance, and results in a high level of autonomy in their work. Bartenders at Copper \& Co. engage in their own form of research: by utilizing social media as well as old-fashioned road trips, the bartenders discover new techniques, spirits, and peers. Gyda and Utah make a point to take trips to nearby cities to sample their cocktail bars, and view this as much a part of their job as wiping down the bar. Visiting other cocktail bars is viewed as both work and pleasure, as the knowledge gained is brought back to their own bar and sometimes implemented. The bartenders view the active accumulation of knowledge as not only enjoyable, but the mark of a committed and serious bartender.

The performative aspect of being a cocktail bartender is also evident in one very important fact: being a bartender means you're behind the bar, face-to-face with the guests. Many respondents likened the experience to being 'on stage': all eyes on you, nowhere to go, and an audience very interested in your performance. Amos mentioned that the difference between serving and bartending was simple: a server is like the magician's assistant that brings all the props to the stage, while the bartender is the magician. The people behind the bar receive the most attention, and therefore must constantly perform. While this may seem to lessen their autonomy (they're in full view of their guests), the fact that their craft knowledge and techniques are not accessible to the layman helps to mitigate any criticism. 
The example mentioned previously of the conflict between the kitchen staff and front of house is a great example of this performance. While the servers could congregate in the dish room or at the server station, the bartenders don't have anywhere to 'hide'. They are in constantly in front of the bar guests, and so keep their cool at all times. There is even a bit of a showy aspect: a few drinks call for torched orange oil, which involves flames unfolding across the surface of the cocktail, and it wasn't unusual to see a bartender with a shaker in each hand, shaking to the beat of the music. These acts, although clearly a bit of fun, play into the 'stage' aspect of cocktail bartending.

\section{Discussion}

The themes that have emerged from the interview process all influence why craft bartenders consider themselves to be professionals. Their store of knowledge, technical skill set, and belief in the performance of professionalism all serve as standards against which they judge themselves and others within the profession. The bartenders' skills, knowledge, and performance contain the elements of occupational professionalism: skill, autonomy, and self-regulation. By examining these factors, where craft bartenders fit within the grand scheme of professions can be found.

\section{The Role of Knowledge}

Knowledge of spirits and cocktails has been addressed extensively in interviews, and clearly factors into how a craft bartender views themselves and the work of all bartenders within the craft industry. Professionals, according to respondents, are largely professionals because of 
the accumulation of capital in their respective field, and knowledge is a prominent form of capital. An individual's store of knowledge affects cocktail bartending in several ways.

First, it factors into self-regulation by acting as a status ranking between bartenders. Professionals, according to Hughes (1963), accumulate a large store of knowledge not readily available to the common man. This claim to intellectual superiority sets craft bartenders aside from not only "volume" bartenders at sports bars or clubs, but it also separates them from one another. Several of the respondents reported 'judging' another bartender on their knowledge and ability by asking for a craft cocktail that wasn't on the menu. If a bartender at a craft cocktail lounge could not make a Last Word or a Vieux Carre, they were looked down upon as not really being in the profession. These, stated Gyda, are classic, simple cocktails that anyone in the industry should be able to make. Individuals who are unable to craft classic cocktails do not have the exemplary knowledge that sets bartenders apart, and are thusly excluded from the craft bartenders' profession.

Knowledge also plays a part in the autonomy of the bartenders. An important distinction between the types of knowledge possessed different types of bartenders is the status ranking associated with the knowledge. Bartenders are employed in a field centered almost entirely on consumption and taste, and craft bartenders must be knowledgeable about the high status that their products convey. This high-status knowledge serves to separate the craft bartender from their clientele, as well as from other types of bartenders. A volume bartender may have less job autonomy because their drinks and skill can be more easily evaluated by an outsider; mixing a rum and coke does not require specialized knowledge. However, a craft bartender, engaged as they are in specialized forms of craft production, is more difficult to evaluate, as their methods and ingredients are largely alien to the consumer. While lower class consumers may have 
different tastes than their counterparts, many individuals still aspire to have 'good taste', and the bartenders possess the high status that allows them to make authoritative judgments on good versus bad taste.

How exactly craft bartenders make taste decisions is not clear to their guests, and so legitimate, evaluative criticism is difficult. Customers unfamiliar with the high-class taste replicated by the craft bartender face a dilemma: if they don't like their drink, do they dislike it because the bartender did a bad job, or do they dislike it because they just have 'bad' taste? If the answer is the former, they struggle with how to criticize the bartender; if the latter, then they must take the bartenders advice, train their tastebuds, and learn to appreciate good taste. Many customers make the latter deduction, as the professional knows best, and therefore can educate his client on the 'right' and 'wrong' ways of partaking in the professional's services (Hughes 1963), The obscure ways in which bartenders make taste judgements contributes to high worker autonomy: they have free range to perform as they see fit, as only other craft bartenders can accurately judge their output.

Craft bartenders take pride in their craft knowledge of obscure spirits, imported wines, and high-quality ingredients because a certain amount of status and capital are associated with these things. Craft cocktails, by being time-consuming to make and expensive, appeal to the taste of high-class consumers. By associating themselves with these high-status goods, cocktail bartenders adopt the associated high class status, and this status attainment distances them from other types of bartenders (Gronow 1997: 33). Though not entirely ignorant of lower-quality spirits familiar to volume bartenders, craft bartenders choose to focus their attention solely on the demands of their particular niche. They are not familiar with 'party' drinks because it is not relevant to their jobs, and the lower status associated with these types of drinks is a threat to the 
craft bartender's claim to esoteric, high-brow knowledge. Bowing to low-class taste by making single-mix drinks from low-quality spirits is, to craft bartenders, akin to medical doctors being compliant in chemical-assisted capital punishment: the violation of basic principles taints the profession, and this informal method of control influences the professional's behavior (Haines 1989: 451). Refusing to take part in low-status taste production is also a part of the informal selfregulation done by craft bartenders. By maintaining the boundary between their craft and the work of other bartenders, respondents strove to protect their reputations and keep their ranks 'pure'.

\section{Service and Technical Skills}

Service and technical skills as they relate to craft production are an alternate form of knowledge that differentiates bartenders from one another, and that plays into the skill factor of professions. Accumulating knowledge of craft bartending, whether from frequenting cocktail bars or reading bar books, is an advantageous way to acquire a certain amount of capital. However, the knowledge can only take you so far within a work setting, and this is when technical skills in the hospitality industry really come into play. For example, several craft cocktails are made with egg whites, and failing to shake the cocktail long enough or vigorously enough will result in a subpar, slightly slimy drink.

Craft bartenders are trained extensively in the skills of their profession, and those who don't have the correct skill set are excluded from the group. Self-regulation comes into play here: those whose skills are considered unacceptable are not embraced as true professionals.

Bartenders who possess the skills and the knowledge to build a drink in the correct manner are not only considered more professional, they are more respected (by both coworkers and 
customers) within Copper \& Co. Alice, a server at Copper, specifically mentioned how a few bartenders at Copper do not possess the proper technical skills when making drinks: they rush through the motions, and as a result the drink is unpalatable. These bartenders need more training, she insists, before they can be considered professionals. The elevated level of respect and deference shown to established and skilled craft bartenders is a form of capital within the industry, and respondents insisted that this is a pattern also at play in other cocktail bars.

Attention to detail is also an essential trait for a bartender. A Vieux Carre is not complete without its garnish, and adding four drops of bitters instead of two can ruin a cocktail. Bartenders who can skillfully perform their jobs quickly and effectively accumulate an enormous amount of capital within the field of craft bartending. Those with more capital are respected more than those with less capital, by both bar guests and coworkers. Amos, for example, cited two of his coworkers as professional bartenders, but declined to ascribe that honor to anyone else in the establishment. His reasoning was that they were simply the best at what they do, whether it be crafting drinks well, crafting them quickly, or crafting them creatively. This elevated respect can result in preferential treatment, and this leads to successful workers being scheduled for busy shifts by the boss. This is another example of how self-regulation occurs within craft bartending: the bartenders themselves often decide who is worthy of respect and deference.

Informal methods of self-regulation also occur during training. When discussing hiring, owner Tim stressed that he hired employees that he thought would be a good 'fit'. He mentioned that good employees were naturally curious, willing to learn, and possessed a good work ethic. They also had to be 'teachable', i.e., humble enough to take direction and interested in how Copper \& Co. functioned as an establishment. While there is no formal booklet that outlines 
proper hiring procedures at Copper \& $\mathrm{Co}$, an applicant was not hired if they did not properly embody these preferred traits during an interview.

Tim also mentioned that a new employee, regardless of the position they applied for, was rarely shuffled straight to the bar. Everyone starts as a server, and if they possess the 'teachability' and work ethic that Copper's employees hold in high regard, they will eventually be moved to bartending. In addition, those who are trained on bar but don't 'work out' are moved back into serving, effectively cutting them off from any bar opportunities in the future. In this way, informal methods of self-regulation play a role in not only hiring, but in moving employees vertically to new positions within the restaurants' hierarchy.

Annie, the server who resigned during the research period, is a good example of this: she cited not being moved to the bar as a reason for her resignation, despite repeated requests. Annie believes that the other bartenders, as well as the owners, didn't believe she would make a good bartender for a variety of reasons, and thus denied her pleas to be moved upward. She mentioned that they may think she's too "spacy" (inattentive) and lacked the formalized communication skills to be a good fit behind the bar. In short, she did not meet the bartender's standards, and the employee-sanctioned methods of self-regulation worked to remove her from the bartending pool. This form of self-regulation is informal in that it does not take the form of an accredited, written skills exam that bestows professional status (Collins 1979); however, it is almost as equally effective at keeping those out of the profession that, in the bartenders' view, don't deserve to be a part of it. Maintaining the boundaries of the bar keeps the profession 'pure' and allows it to hold on to the capital that is associated with doing high-class work.

In addition, the high level of autonomy of the workers enjoy largely stems from their craft production skills. As mentioned earlier, the process by which craft bartenders assign value 
to their products is not easily discernable to those not in the occupational group. Bartenders have a large amount of creative license in their work largely because consumers rely on their training and skills in the production of a tasteful cocktail. While bar guests were observed asking the bartenders questions about their work, the questions were often value-neutral ("what does this taste like?"), and guests largely accepted the bartenders' answers and suggestions without criticism. The interaction between bartenders and guests who are not sure what to order is an excellent example of this. A guest asks the bartender to make them something bitter and with whiskey, and essentially leave the rest up to the bartender. A guest rarely asked why the bartender was adding an ingredient to a cocktail, let alone why they chose that particular spirit over another. Customers are not familiar with the in-between work of the craft bartender; the relationship between what they ask for and what is made is often obscured. This results in a high level of creative license for the craft bartender, and thus a high level of autonomy.

\section{Craft Bartenders as Cultural Intermediaries}

A cultural intermediary is an individual that serves as a type of middleman between symbolic or cultural goods and consumers. Cultural intermediaries have high amounts of cultural capital in the form of knowledge and expertise, and this lets them speak with authority about the worth and value of goods (Bourdieu 1984: 354-65). The value assigned by the cultural intermediaries are judgements based on taste, and so intermediaries must also have a firm grasp and understanding of the tastes of their consumers in order to accurately represent and replicate their preferences. The craft bartenders in this research meet the criteria for cultural intermediaries in several ways. 
First, the bartenders possess high levels of knowledge specific to their trade. They know their menus, their wine and scotch lists, and what they have on the shelf. The bartenders are also familiar enough with the attributes of each ingredient to be able to blend them in a drink. Copper \& Co.'s bartenders are comfortable making drinks from even the smallest of clues, such as "gin and bitter". They are skilled in their techniques of their trade, and know which drinks should be shaken as opposed to stirred, as well as why the drink should be prepared as such. Their required knowledge is seemingly never-ending, and is used as a form of status differentiation within the occupational group. Bartenders actively pursue knowledge by networking and traveling, showing a marked devotion and commitment to the acquisition of specialized knowledge.

An important note, however, is that this specialized knowledge is not readily available to consumers. The sheer volume of things that craft bartenders need to know requires full-time commitment and investment. Indeed, one must also be accepted into the occupational group itself, as many pieces of knowledge are not found in books, but are passed down from bartender to bartender. The opacity of the bartenders specialized knowledge lends them a high amount of autonomy, as discussed earlier; however, it also has the added function of lending the bartenders a fair amount of authority when they discuss drinks. If a guest doesn't know what Pernod or Benedictine is, they cannot criticize a bartenders' use or exclusion of these ingredients. If a bartender insists that a drink is best with a certain type of gin, how is the guest to argue?

A second way that bartenders function as cultural intermediaries is that craft bartenders work within the field of taste, and recognize this fact as part of the reality of their profession. Craft cocktails, much like the game of polo or Kobe beef, suit the taste of high-status consumers. This status association affects craft bartenders in two ways: it sets the standards that their products must meet, and it influences how the bartenders themselves dress, speak, and work. The 
craft cocktails produced by the bartenders necessitate precision and expertise, as consumers paying $12 \$$ for a drink expect a certain level of effort and quality of spirits. A bartender would not be able to please a high-status guest by hurriedly pouring vodka into a plastic cup and throwing a wilted lemon slice in: this does not harmonize with the high-status taste associated with craft cocktails and the population that consumes them.

Taste also affects the habitus of the bartenders. The dress code is designed to appeal to higher-status clientele, such as other professional workers (lawyers, doctors, scientists). By donning a tie and vest instead of a faded t-shirt, Copper's bartenders reflect the taste of their consumers. Their language is also formalized: guests are never referred to as "customers", and groups are always addressed as "ladies and gentlemen". Bartenders as well as servers pay close attention to their postures body language, and facial expressions to make sure that their movements are not too casual; in other words, they alter their behavior to reproduce the high standards of taste that are associated with craft cocktail lounges.

Lastly, bartenders make excellent cultural intermediaries because they literally stand between the guests and the alcohol. The bartender is the one that crafts the drinks, and in many cases, craft bartenders have a heavy hand in making their own cocktail menus. The bar manager (and Sommelier, if there is one on staff) usually make decisions regarding which spirits are available at the establishment, and so influence which goods and symbols they choose to advertise and sell. Even if a consumer insisted that they knew exactly what they wanted, it is to no avail if the bar in question simply does not stock the correct ingredients. This method of controlling the goods within the establishment helps the craft bartenders to retain their highstatus knowledge, spirits, skills, and reputation. 


\section{Conclusion}

This research was conducted with the goal of uncovering what makes craft bartenders professional workers, despite the absence of an accredited standard. Through interviews and observations, several qualifications emerged that craft bartenders use to define and perform their own conception of professionalism. These qualifications rank craft bartenders among other professions with high worker autonomy, high levels of skill, and high levels of self-regulation.

According to the bartenders, servers, and owners of Copper \& Co., a craft bartender is defined as a professional because they possess a specialized knowledge and skill set, and believe in the full performance of professionalism. The type of specialized knowledge, skill, and behavior that craft bartenders possess mirror the high-class tastes in society, thus lending craft bartenders a type of capital that other types of bartenders do not possess. These high amounts of high-status knowledge and specialized skills result in increased respect and deference afforded to craft bartenders, and support the conceptualization of craft bartenders as both professionals and cultural intermediaries.

In addition, the high level of autonomy found within craft bartending also supports the idea of craft bartenders being professional workers. The bartenders specialized knowledge of their job is readily available to those within the occupational group, and not easily accessed by customers. As a result, bartenders are rarely questioned, doubted, or effectively criticized by their clients. They have free reign to do their jobs in the way they see fit, so as long as they ascribe to the high-status standards and informal regulations set forth by their peers. This level of autonomy places bartenders within the field of professionals, and contributes to the conceptualization of bartenders as cultural intermediaries with the power to ascribe value to goods. 
The self-regulation practiced by craft bartenders is effective at maintaining boundaries, even though it is informal. Many self-regulatory mechanisms within established professions take the form of exams, schooling, and official tests; however, the self-regulation within craft bartending largely relies on social pressure and informal standards of conduct. This bartenders at Copper \& Co. insisted in their interviews that they have the same standards as other bartenders across the nation. Their visits to other cocktail bars, networking, and previous employment at similar establishments were used to support this claim. Whether all craft bartenders hold the same standards may be in question, but the effectiveness of their informal gatekeeping strategies is not. Whatever their standards are, they work hard to make sure that their peers meet the requirements, lest they soil the good name of a craft bartender. This high level of self-regulation also places craft bartenders within the professional occupation group.

In closing, the results from this case study support the idea that craft bartenders, through high levels of autonomy, skill, and self-regulation, are professional workers. Craft bartenders also act as effective cultural intermediaries, as they have the knowledge, authority, and autonomy required to make value judgements of their goods based on the high-status taste ascribed to their work. A potential direction for future research is to expand the scope of this study to include multiple other craft cocktail and fine dining establishments. Although the employees at Copper \& Co. agreed on the qualifications of a craft bartender, it is important to note that this is a single case study, located at a small restaurant, in a college city. Larger establishments in more metropolitan areas should be studied as well, to investigate whether they hold similar ideas of professionalism. 


\section{References}

Abbott, Andrew D. 1993. "The Sociology of Work and Occupations." Annual Review of Sociology, 19: 187-209.

About the NLA. (2015). Retrieved March 2017, from National Lawyers Association: http://www.nla.org/adout-nla/

Bell, Quentin. 1992. On Human Finery. London: Allison \& Busby.

Bourdieu, Pierre. 1984. Distinction: A Social Critique of the Judgement of Taste. Cambridge, MA: Harvard University Press.

Bourdieu, Pierre. 1986. "The Forms of Capital". Pp 241-258 in Handbook of Theory and Research for the Sociology of Education, edited by J. Richardson. New York, New York: Greenwood.

Bourdieu, Pierre., \& Passeron, Jean-Claude. 1979. The Inheritors: French students and their relation to culture. Chicago: University of Chicago Press.

Brown, JoAnne. 1992. The Definition of a Profession: the Authority of Metaphor in the History of Intelligence Testing, 1890-1930. Princeton, New Jersey: Princeton University Press.

Collins, Randall. 1979. The Credential Society: A Historical Sociology of Education and Stratification. New York, New York: Academic Press.

Florida, Richard. 2002. The Rise of the Creative Class. New York, New York: Basic Books. Freund, Peter., \& McGuire, Meredith. 1995. Health, Illness, and the Social Body: A Critical Sociology. New Jersey: Prentice Hall.

Glaser, Barney. G. (1992). Basics of Grounded Theory Analysis: Emergence Vs. Forcing. Sociology Press . 
Goffman, Erving. 1951. "Symbols of Class Status." The British Journal of Sociology 2(4): 293304.

Goffman, Erving. 1956. The Presentation of Self in Everyday Life. Edinburgh: University of Edinburgh.

Gronow, Jukka. 1997. The Sociology of Taste. London: Routledge.

Haines, Herb. 1989. "'Primum Non Nocere": Chemical Execution and the Limits of Medical Social Control." Social Problems 36(5): 442-454.

Hughes, Everett C. 1963. "Professions." Daedalus, 92(4): 655-668.

Jackson, J.A. 1970. Sociological Studies, Volume 3: Professions and Professionalization (Vol. 3) Cambridge: Cambridge University Press.

Johnston, J., \& Baumann, S. 2007. "Democracy vs Distinction: A study of omnivorousness in gourmet food writing." American Journal of Sociology, 113(1): 165-204.

Kant, Immanuel. ([1790] 1952). The Critique of Judgement. Oxford, England: Oxford University Press.

Koppman, Sharon. (2016). "Different Like Me: Why Cultural Omnivores Get Creative Jobs." Administrative Science Quarterly, 61(2): 291-331.

Larson, Magali. S. 1979. The Rise of Professionalism: A Sociological Analysis. Berkeley, CA: University of California Press.

Maton, Karl. 2008. "Habitus". Pp 49-65 in Pierre Bourdieu: Key Concepts, edited by M. Grenfell. Durnham: Acumen.

Moore, Robert. 2008. "Capital". Pp 101-117 in Pierre Bourdieu: Key Concepts edited my M. Grenfell. Durnham: Acumen. 
Ocejo, Richard. 2011. ""What'll it be? Cocktail Bartenders and the redefinition of service in the creative economy". City, Culture, and Society. 179-184

Ocejo, Richard. 2012. "At your service: The meanings and practices of contemporary bartenders. European Journal of Cultural Studies". 15(5): 642-658.

Profession. (n.d.). Retrieved March 2017, from Merriam-Webster Online Dictionary: https://www.merriam-webster.com/dictionary/profession

Simmel, Georg. [1904] 1957. "Fashion". American Journal of Sociology, 62(6): 541-58.

Thomson, Patricia. 2008. "Field". Pp 67-81 in Pierre Bourdieu: Key Concepts, edited by M. Grenfell. Durnham, UK: Acumen.

Veblen, Thorstein. [1899] 2005. The Theory of the Leisure Class; An Economic Study of Institutions. Delhi, India: Aakar Books.

Weiss, Robert. S. 1994. Learning From Strangers. New York, NY: The Free Press.

Wondrich, David. 2007. Imbibe! From Absinth Cocktail to Whiskey Smash, a Salute in Stories and Drinks to "Professor" Jerry Thomas, Pioneer of the American Bar. New York, NY: Penguin Group.

Woodward, Iain, \& Emmison, Michael. 2001. "From aesthetic principles to collective sentiments: The logics of everyday judgements of taste." Poetics, 29: 295-316. 


\section{Appendix I: Participants}

\begin{tabular}{|l|l|l|l|l|l|}
\hline \multicolumn{1}{|c|}{ Name } & \multicolumn{1}{|c|}{ Age } & \multicolumn{1}{|c|}{ Sex } & \multicolumn{1}{c|}{ Race } & \multicolumn{1}{c|}{ Position } & \multicolumn{1}{c|}{$\begin{array}{c}\text { Years } \\
\text { employed }\end{array}$} \\
\hline Tim & & Male & White & Owner & Owner \\
\hline Chuck & & Male & White & Owner & Owner \\
\hline Vladimir & 36 & Male & White & $\begin{array}{l}\text { Bartender/ head } \\
\text { server/ sommelier }\end{array}$ & 2 years \\
\hline Johnny Utah & 29 & Male & White & $\begin{array}{l}\text { Beverage director/ } \\
\text { bartender }\end{array}$ & 2 years \\
\hline Gyda & 22 & Female & White & Bartender & 2 years \\
\hline Emilia & 28 & Female & White & Server & $2 \sim$ years \\
\hline Annie & 22 & Female & White & (ex) Server & 1.5 years \\
\hline Alice & 23 & Female & White & Server & 2 years \\
\hline Amos & 23 & Male & White & Bartender/server & 8 months \\
\hline Sampson & & Male & White & Bartender/server & $7-8$ months \\
\hline
\end{tabular}




\section{Appendix II: Interview Guides}

\section{Background questions}

\section{Bartending Questionnaire/ Interview guide}

How did you become a bartender?

a. How long have you been a bartender? How did you get into bartending?

b. Who taught you to bartend? Are you self-taught or did you receive training?

c. How did you get your start at cocktail bars?

- Have you been a bartender at other types of establishments?

- Is the clientele different? How?

- Do you get more respect from guests here than at your other jobs?

d. Do you go to other cocktail bars?

a. If so, how do you judge the performance of other cocktail bartenders?

The job

a) Do you enjoy your job? Why or why not?

a. Most enjoyable part of the job? Least?

b) Do you make drink recommendations for guests? Do they ask first?

c) What do you consider to be the most important traits or skills for someone in your job?

d) Do you see yourself bartending in 10 years?

a. Why or why not?

\section{Professionalization}

Do you consider yourself to be a professional? A craftsman?

b. Why? (or why not?)

i. Difference between professional vs craftsman

ii. What makes you a professional?

iii. How do you prove that you're a professional?

iv. Do other people treat or refer to you as a professional?

c. Do you have any licenses or professional paperwork for bartending?

$i$. If not, then how do you measure proficiency at the job?

ii. If so, what is the process? Are the official papers important?

d. What makes you $\&$ your job different than a bartender at [less fancy] bar?

e. Could a 'normal' bartender do your job, or vice versa? Why or why not?

f. Who is the best bartender you know? What makes them the best?

g. Managerial:

i. How do you recruit \&/or hire people?

ii. What do you look for in an employee?

iii. What makes a "good" or "fitting" job candidate for bartending? Serving?

$i v$. Have you ever had an applicant that looked good on paper but blew the interview? 


\section{$\underline{\text { Server Questions/ Interview Guide }}$}

1) How long have you worked at this restaurant?

a. How did you come to work at this restaurant?

2) What was your training experience like?

3) What is the best part of your job? The worst?

4) Do you have any bar experience?

a. Yes: please describe in detail

b. No: why do you think not?

5) What do you think about the bar?

a. The bartenders?

6) Do you think the bartenders here are professionals?
a. Why? Why not?
b. Characteristics?
c. What makes a professional?

7) What are the differences between the servers and the bartenders?

8) Any last opinions, thoughts, about the bar and bartenders?

\section{Managerial Questions:}

1) HISTORY

a. Is this the first restaurant you've owned?

b. Past experience in service/ hospitality?

2) Tell me about your vision or goal for this restaurant

a. Where does it fit in the city's food and drink scene?

3) Tell me about your employees

a. Bartenders, servers, kitchen

b. What do you look for?

i. Hiring people

ii. Moving people

c. What makes a good bartender? A good server?

4) What is your hiring process like?

5) What are your opinions about cocktail bartending and craft production?

6) Do you consider your bartenders to be professionals?

a. Why not?

b. Who is? 